\title{
Cellulose for the Effective Decontamination of Water Pollution
}

Bryan Aldaz' Freddy Figueroa ${ }^{2}$ and Isaac Bravo ${ }^{3}$

DOI. 10.21931/RB/2020.05.02.13

Abstract: The widespread industrialization, urbanization, and technological development have triggered the daily release of considerable amounts of pollutants, specifically in aquatic environments. Previous research and work-studies indicate the existence of defined properties, such as low cost, non-toxicity, biodegradability, reusability, and easy synthesis, preparation or extraction, which make a material an ideal agent for the remediation of water or the environment. Therefore, the scientific community has focused on the development and study of several novels, environmentally friendly, and cost-effective materials. Cellulose is the most abundant natural polymer encountered worldwide. Thereby, due to the unique biological properties that this biopolymer possesses, it has emerged as a potential candidate to replace synthetic materials for practical bioremediation of contaminated water. Furthermore, the presence of hydroxyl groups on its surface makes this biopolymer highly malleable, thus significantly enhancing its physicochemical properties by using a wide variety of functional groups and modification methods. The present review describes the different biopolymers useful for remediation of environmental pollution, explores in more detail the characteristics of cellulose and its promising applications in the decontamination of water pollution, and pays special attention to the removal of heavy metal ions, dyes, and hydrophobic organic compounds.

KeyWords: cellulose, water pollution, water decontamination, biopolymers, biodiversity.

\section{Introduction}

In the last decade, one of the significant threats concerning the environment is the alarming growth rate of industrialization, urbanization, and technological development ${ }^{1-3}$. Environmental contamination is commonly classified into the air, water, and soil pollution ${ }^{2}$. Due to the high importance and value of the limited water resources for all the living beings, it is of fundamental interest to explore efficient and safe solutions for the proper decontamination of water resources ${ }^{4,5}$. Water pollution is defined as the disturbance of the quality and the standard conditions of any aquatic environment by either organic or inorganic foreign matter ${ }^{6}$. Numerous hazardous contaminants are daily released by diverse anthropogenic sources such as industrial procedures, food processing clothing manufacturing, landfills, plastic production, medicine development, and pesticide usage ${ }^{3,7-10}$. The most common contaminants present in the different types of pollution (i.e. water, air, and soil) are carbon monoxide, chlorofluorocarbons, heavy metals (arsenic, copper, chromium, lead, cadmium, mercury, and zinc), hydrocarbons, chemical wastes, nitrogen oxides, organic compounds (volatile organic compounds and dioxins), sulfur dioxide, pesticides, and particulates ${ }^{11,12}$.

Additionally, pollution can lead to the development of multiple diseases negatively influencing human wellness ${ }^{13,14}$ Hence, environmental pollution harms the ecosystems and the biodiversity of the world. Drinking contaminated water with pesticides or heavy metal ions is related to the development of tumors in almost all organs, immunosuppression, and disruption of the regular hormonal activity, causing damage to the nervous system, as well as the kidney and liver ${ }^{9}$. In the same way, the reason for the appearance of different respiratory, cardiovascular, neurological diseases, adverse effects on the endocrine system, and the neurodevelopment in infants is attributable to the exposure to water pollution 9,14 .

\section{Current Remediation Technologies for Water Pollution Decontamination}

Currently, nanotechnology approaches, different materials, and novel technologies have been explored and studied by the academia and scientific community to remediate the water contamination ${ }^{11,15-23}$. The use of various organic and inorganic materials, the implementation of nanotechnology, and the manipulation of particles at the nanoscale have been the most studied and developed decontamination methods in the literature ${ }^{24}$. Also, it has been reported that porous nanoscale materials (NMs), NPs-TiO , Graphene-based NMs, Titanate Nanotubes, Fullerenes, Silica Nanocomposites or Polymeric-based NMs can be used as adsorbents for different contaminants, water decomposition agents or can either enhance the microbial degradation of waste and toxic materials or directly catalyze them $2,25,26$. Notwithstanding, these innovative methods have been gaining much attention from the academy, and from governmental organizations, NMs have demonstrated to be unstable at standard conditions, present synthesis complexity, and may create adverse toxic byproducts once used ${ }^{2}$. The process of synthesis of $\mathrm{NMs}$ is expensive, without mention their lack of renewal or reuse capacity, turning them eventually into new pollutants. Consequently, only a few nanotechnologies approach for remediation of polluted water can be finally marketed ${ }^{27}$

\section{Sustainability of Biopolymers}

Several studies point out the existence of defined properties that would make a material a suitable agent for the decontamination of water pollution, features such as costeffectiveness, non-toxicity, biodegradability, biocompatibility, reusability, and ease of synthesis, preparation or extraction ${ }^{15}$. These critical properties are all characteristics of natural polymers encountered in the biodiversity, listed in Table 1. Based on their physicochemical and environmentally friendly properties, academia and governmentally organizations have been strongly interested in the development and exploration of biopolymers to find efficient and greener solutions to environmental issues and concerns ${ }^{28}$.

${ }^{1}$ School of Biological Sciences and Engineering, Yachay Tech University, Urcuquí, Ecuador. 

$\begin{array}{ll}\text { Cellulose } & \begin{array}{l}\text { Removal of different contaminants (HOCs and VOCs) from } \\ \text { water and air pollution }\end{array}\end{array}$

Chitosan Water purification
$(29,30)$

(7)

\section{Alginate Removal of dyes and heavy metals}

Table 1. Most common biopolymers and their applications in environmental pollution decontamination.

\section{Chitosan}

Chitosan is a linear polysaccharide obtained by the incomplete alkaline deacetylation of chitin. This biopolymer is known to be the second most abundant polysaccharide in Earth after cellulose ${ }^{34}$. Usually, it is mainly extracted from the exoskeletons of crustaceans, shrimps, and crabs' shells ${ }^{35}$. The structure of chitosan is composed of $b$ - $(1,4)$-2-acetamido2-deoxy-D-glucose and b-(1,4)-2-anaino-2-deoxy-D-glucose monomers as building blocks repeats. This biodegradable polymer has a wide range of potential applications, including food preservation, packaging technologies, rice production, and tissue regeneration technologies, among others ${ }^{34,36,37}$. According to Alaa Jabbar et al. (2016), chitosan had been widely used in water purification plants to effectively remove oils, grease, and heavy metals in contaminated water ${ }^{38}$. Moreover, Zhao et al. (2019) proved that carboxylated chitosan composite beads were useful materials for the efficient adsorption and immobilization of $\mathrm{Cu}^{2+}$ ions in contaminated water and soil ${ }^{39}$. Thus, several studies have demonstrated the remediation potential of chitosan for decontamination purposes of the environment ${ }^{40}$.

\section{Alginate}

Alginate is an anionic biocopolymer mainly composed of an alternative repeating of blocks of glucuronate and mannuronate. This biomaterial is commonly extracted from brown seaweed (Phaeophyceae); its extraction methodology requires the use of strong bases, salts, and acid treatments, such as $\mathrm{NaOH}, \mathrm{NaCl}$, and dilute $\mathrm{HCl}$. Based on its promising biological properties (i.e., biocompatibility, low toxicity, relatively low cost, and mild gelation), alginate has been extensively used in different biomedical applications. Diverse studies depicted the use of alginate in wound healing and applications in tissue engineering, as well as its use in drug delivery systems for the release of a variety of bioactive agents ${ }^{41}$. In 2018, Wang et al. extensively described the utility and application of different alginate-based composites as effective biosorbents for environmental remediation objectives. Thereby, they successfully demonstrated the great potential of these hybrid biomaterials for the removal of dyes, heavy metals, antibiotics, and other pollutants from contaminated water $^{31}$.

\section{Lignin}

Lignin is a racemic heteropolymer composed of aromatic subunits derived from phenylalanine. In nature, lignin provides mechanical support to plant cell walls; it is synthesized from the oxidative coupling of three hydroxycinnamyl alcohol monomers that differ in their methoxylation degree: p-coumaryl, coniferyl, and sinapy ${ }^{42}$. Currently, lignin is a biomaterial with prevalent importance in the industry. There are many examples that demonstrate how lignin can improve the efficiency of the industrial procedures in the manufacturing of products derived from plant biomass, forage digestibility and, enhancing the process of fabrication of biofuels from the recollection of feedstock until their application or commercialization ${ }^{43}$. Many studies have been conducted to assess the feasibility of ligninbased gels and green porous lignin-based spheres as potential heavy metal capturing agent for bioremediation. As reported by Parajuli et al. in 2005, the application of lignin-catechol complex gels exhibits optimal low cost, simple preparation, and biodegradation properties. Besides, this complex presents excellent adsorption characteristics for the assessed cations, such as $\mathrm{Pb}^{2+44,45}$.

\section{Silk}

Silk is a natural fiber produced mainly by certain spiders to build their cocoons or webs ${ }^{46}$. Although silk is produced by many insects, only the filaments made by the mulberry silk moth Bombyx mori are commercially available owing to their biocompatibility, biodegradability, non-toxicity and adsorption properties ${ }^{47}$. In addition, silk produced by spiders can be used in other commercial applications, for instance, weapon and telescope cross-hairs and other optical instruments ${ }^{46}$. Due to their mechanical qualities of strength, elasticity, softness and other features, such as improved absorbency, an affinity for dyes, and great adaptability to various forms of twisting, natural silk fibers have been recognized as a promising biomaterial suitable for the development of surgical threads and wound dressing, to name a few ${ }^{48}$. Moreover, Wang et al. (2016) have reported a human-friendly, high efficient, and lightweight silk nanofiber air filter which exhibits not only a considerable filtration efficiency for submicron and particulate matter but also antibacterial activity demonstrating that this biopolymer is appropriate for remediation of air pollution ${ }^{33}$.

\section{Cellulose Applications for the Remediation of the Water Pollution}

Cellulose is the most abundant biopolymer available worldwide $4,49,50$. This biomaterial is a highly ordered crystalline polysaccharide consisting of parallel arrays of $\beta-1,4-$ linked glucose chains ${ }^{49}$. Several studies suggest that the characteristic cellulose high order structure is the result of basic dimer repeats, known as cellobiose ${ }^{51-53}$. Also, these dimer repeats are described in the literature as two D-glucopyranose units linked by $\beta$-1,4-glycosidic bonds ${ }^{4,54-56}$. Moreover, cellulose 
chemical structure is based on the presence of strong $\mathrm{H}$-bonds between their multiple hydroxyl groups, which confers its unique physicochemical features such as hydrophilicity, chirality, crystallinity, or biodegradability ${ }^{57}$. Furthermore, the highly dense $\mathrm{OH}$-groups on its surface structure allows this natural polymer to be readily functionalized and modified by diverse chemical methods using a variety of functional groups to hence enhance and modify its physicochemical properties. This makes cellulose a versatile and malleable material ${ }^{55}$. As a result, cellulose has been of particular interest due to its low cost, availability, flexibility, secure processing, nontoxic, and biodegradable properties, emerging as one of the most promising substitutes for synthetic and fuel-based materials $21,50,58$

Cellulose is a water-insoluble material and a crucial component in the structural maintenance of plant cell walls ${ }^{56}$. Nowadays, there are several well-known sources for cellulose, such as plants, algae, bacteria, or sea animals: Thanks to their abundance and economic viability, plants have been so far the primary source of cellulose extraction ${ }^{29,56,59}$. Indeed, the most common cellulose sources are wood pulp and cotton linders. Besides, agricultural wastes such as sugarcane bagasse, fruits, grasses, or rice straws, are other sustainable plant sources to produce cellulose. Bacterial cellulose is unique as it offers several advantages over plant-derived cellulose (i.e., unique nanostructure, purity, higher-dimensional stability, higher mechanical strength, and polymerization). Additionally, the marine invertebrate Tunicates are well-known for assembling cellulose. These sea animals use cellulose as a skeletal structure in their leathery mantle tissues, which is produced by enzyme complexes found in the membrane of the tunicate epidermis ${ }^{50}$.

Per the excellent and promising biological properties that biopolymers possess, cellulose has emerged as the perfect decontamination agent for the development of greener and improved environment remediation technologies, as illustrated in Fig. 1. Moreover, Latin America (LATAM) biodiversity plays an essential role as the ideal scenario for the extraction of an abundant unique variety of cellulose fibers ${ }^{60,61}$. LATAM houses a significant fraction of the world's biodiversity, including the most abundant biomes on Earth. The richness in flora and fauna of the Amazonian biodiversity plays an essential role in the securing of unique, diverse, and eco-friendly native biomaterials mentioned above ${ }^{61}$. Despite its small size (250.000 $\mathrm{km}^{2}$ or $1.5 \%$ of South America extension), Ecuador hosts $18.000-22.000$ species of plants, ranking it among one of the most biodiverse countries in the world ${ }^{62,63}$. Therefore, numerous studies have focused on the usage of different cellulose-based materials extracted from biodiversity that can effectively adsorb or capture water contaminants, 20,29,39,64-66. Besides, the literature has shed light onto the mechanism and the physicochemical properties related to the performance of these biopolymers, since it is of paramount consideration that the scientific community clearly understands that natural sources play along with the remediation capabilities of cellulose ${ }^{32,67,68}$.

The most common methods described in the literature for removing contaminants from polluted water include sorption, chemical precipitation, and electrochemical treatment, among others. Of these, the sorption remains one of the most effective and efficient processes ${ }^{20,69}$. Some cellulose-based adsorbent is commonly used for heavy metal, and dyes removal from wastewater and are listed in Table $2^{70}$.

As a consequence of the easy modification of cellulose by a vast number of functional groups and via chemical or physical methods, one of the first applications of functionalized cellulose is the remediation of contaminated water from heavy metals and different residues contaminants. For instance, Tursi et al. (2018) demonstrated that cellulose fibers with a hydrophobic surface extracted from Spanish Broom (SB) are a suitable material for the fast and significant adsorption of hydrophobic organic compounds (HOCs) present in water pollution. Specifically, this research team modified the surface of SB cellulose fibers by chemical nebulization protocols using 4, 4'-diphenylmethane diisocyanate to remove the hydrophilic surface properties of the polymer. After confirming the functionalization of the cellulose is confirmed by XPS and ATRFTIR, they performed batch experiments to test the absorption kinetics and capacity of the fibers to remediate polluted water with gasoline petrol. As an outcome, these functionalized SB cellulose fibers could adsorb petroleum hydrocarbons with efficiency higher than $90 \%$ within a few minutes, which makes this biomaterial a novel green technology for the remediation of polluted water ${ }^{29}$.

Gamze et al. screened the ability of cellulose graft copolymers to remove heavy metal ions from aqueous solutions. They considered the ion-exchange property of the biomaterial and studied the competitive replacement of $\mathrm{Pb}^{2+}$, $\mathrm{Cu}^{2+}$, and $\mathrm{Cd}^{2+}$ ions. The copolymers used were celluloseg-polyacrylic acid (cellulose-g-pAA) with different grafting percentages, cellulose-g- $\mathrm{p}(\mathrm{AA}-\mathrm{NMBA})$ prepared by grafting of acrylic acid (AA) onto cellulose in the presence of the

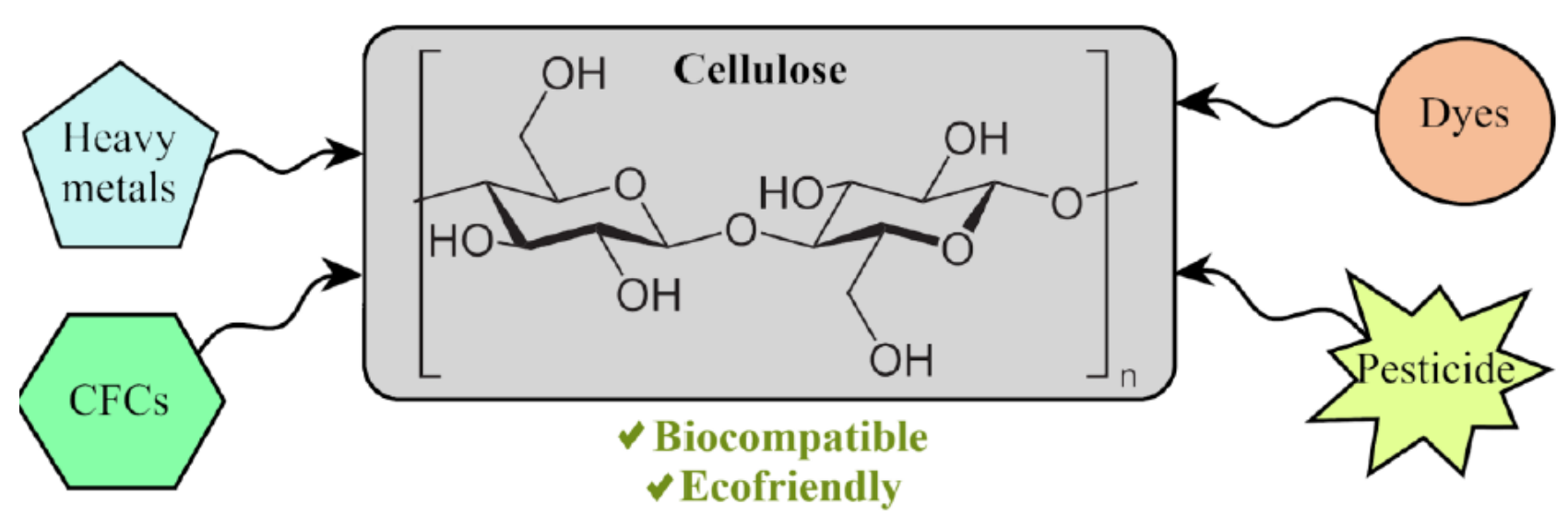

Figure 1. Cellulose is considered one of the best environment remediation agent candidates due to its unique biological properties and economic sustainability. 


\begin{tabular}{|c|c|c|c|}
\hline Cellulose-based adsorbent & $\begin{array}{l}\text { Dyes/Heavy } \\
\text { metals }\end{array}$ & $\begin{array}{c}\text { Adsorption } \\
\text { capacity (mg/g) }\end{array}$ & \\
\hline Grass waste & Methylene blue & 457.64 & $\begin{array}{l}\text { Table 2. Adsorption capa- } \\
\text { cities of cellulose-based }\end{array}$ \\
\hline Jack fruit peel & Basic blue 9 & 285.71 & $\begin{array}{l}\text { material for heavy metal } \\
\text { and dyes removal from }\end{array}$ \\
\hline Spent tea leaves & Methylene blue & 300.05 & wastewater. \\
\hline Mosambi (sweet lime) peel & $\mathrm{Cr}(\mathrm{VI})$ & 250 & \\
\hline Cucumber peel & $\mathrm{Pb}$ (II) & 133.60 & \\
\hline Sunflower stalk & $\mathrm{Cd}$ (II) & 69.80 & \\
\hline Orange peel & $\mathrm{Cu}$ (II) & 63 & \\
\hline
\end{tabular}

crosslinking agent $\mathrm{N}, \mathrm{N}$-methylene bisacrylamide (NMBA), cellulose-g-p(AA-AASO3H) prepared by grafting a monomer mixture of $A A$ and 2-acrylamide-2-methyl propane sulfonic acid (AASO3H), and cellulose-g-pAASO3H obtained by grafting of AASO3H onto cellulose. Their results showed that all types of cellulose graft copolymers exhibited a selective removal of the previously mentioned heavy metal ions ${ }^{71}$. These findings corroborate the result published by Waly et al. who demonstrated that among many copolymers investigated (e.g., glycidyl methacrylate, dimethyl aminoethyl methacrylate, and polyacrylic acid (pAA)), pAA-cotton cellulose-based copolymer was the most efficient one regarding heavy metal removal, specifically $\mathrm{Cu}^{2+}$ and $\mathrm{Co}^{2+}$, and presented excellent efficiency for capturing basic dyes ${ }^{72}$.

\section{Microcellulose and Nanocellulose for the Remediation of Water Pollution}

As detailed above, nano and microscale cellulose can be obtained from a vast assortment of sources. Due to their unique biological properties, these materials have been extensively used for water remediation. Despite presenting similar biological properties, these materials have exhibited significantly different performances when used as decontamination agents. These differences have been largely explained based on their specific surface area/volume (S/V) ratio variation. For instance, cellulose microcrystals (CMC) compared with nanocrystals $(\mathrm{CNC})$ possess a lower $\mathrm{S} / \mathrm{V}$ ratio, which in turn influences their adsorption capacities and leads to much worse performance. Thus, it is deduced that the smaller the S/V ratio, the lower the percentage of adsorption of water pollutants. Also, comparative analysis between CMC and CNC suspensions showed that CNC suspension presents higher stability, relevant for a more prolonged exposure to the contaminant to be captured ${ }^{73}$. The study of their morphologies and structures demonstrated that $\mathrm{CNC}$ and $\mathrm{CMC}$ have similar functional groups and crystalline structures, as confirmed by FTIR and XRD experiments. TGA analysis indicated that the initial degradation temperatures of CMC and CNC are slightly different. These results improve the understanding of how variations in size can affect the physicochemical properties of commercially available $\mathrm{CMC}$ and $\mathrm{CNC}^{74}$.

Besides the usage of cellulosic materials for the efficient adsorption of pollutants, cellulose nano- and microscale materials can be engineered and explored for the fabrication of filtration membranes for water treatment ${ }^{20}$. According to Honyang et al. (2013), the development of efficient microfiltration membranes was achieved thanks to the integration of ultrafine cellulose nanofibers onto a platform based on a nanoscale layer of polyacrylonitrile (PAN) deposited on a microscale polyethylene terephthalate (PET) film. They proved that the high surface area and large pore density were critical parameters that could enhance the retention of bacterial (Escherichia coli), heavy metals (e.g., $\mathrm{Cr}^{4}$ and $\mathrm{Pb}^{2}$ ), and viruses (MS2 bacteriophage), which constitute the common pollutants encountered in contaminated water samples. The researchers successfully demonstrated that ultrafine cellulose nanofibers could remove toxic contaminants and thus, becoming a promising tool for water purification ${ }^{21}$.

\section{Conclusions}

The fast growth rate of industrialization has seriously affected the different water sources of Earth. Furthermore, many organic and inorganic materials, along with the development of nanotechnology-based approaches have been described throughout the literature as non-suitable methods for the decontamination of the environment, since they lack biological and sustainable properties. Thereby, biopolymers extracted from the biodiversity emerged as appropriate remediation agents for the purification and decontamination of water sources due to their intrinsic unique physicochemical properties. Numerous research works detailed in this review have demonstrated that biopolymers are suitable and sustainable materials for the remediation of water pollution.

Cellulose possesses the properties of an ideal biomaterial: It is the most abundant biopolymer on Earth, cheap, non-toxic, biodegradable, biocompatible, and highly versatile. Additionally, the rich flora and fauna of Latin America biodiversity plays a vital role in the securing, synthesis, and development of unique, diverse, and eco-friendly native cellulose-based materials. Finally, different research projects using numerous cellulosic materials have demonstrated its malleability in the field of bioremediation making it an excellent alternative to synthetic polymers, and so proving that biopolymers, but more importantly cellulose, are a green and better solution for the remediation of the environment.

\section{Bibliographic references}

1. Muralikrishna VI, Manickam V. Chapter one: Introduction. In: Environmental Management: Science and Engineering for Industry. 2017. p. 1-4.

2. Bhandari G. Environmental Nanotechnology : Applications of Nanoparticles for Bioremediation. Approaches in Bioremediation. 2018;301-15.

3. Inyinbor Adejumoke A, Adebesin Babatunde O, Abimbola O, Tabitha A, P OA, A AT. Water Pollution : Effects, Prevention, and Climatic Impact, Water Challenges of an Urbanizing World, IntechOpen. 2018;

4. Bethke K, Palantöken S, Andrei V, Roß M, Raghuwanshi VS, Kettemann F, et al. Functionalized Cellulose for Water Purification, Antimicrobial Applications, and Sensors. Adv Funct Mater. 2018;28(23):1-14.

5. Barakat MA. New trends in removing heavy metals from industrial wastewater. Arab J Chem. 2011;4(4):361-77. 
6. Verma R, Dwivedi P. Heavy metal water pollution- A case study. 2013;5(5):98-9.

7. Kumar V, loan S. Recent advances in cellulose and chitosan based membranes for water purification : A concise review. Carbohydr Polym. 2016;146:148-65.

8. Duruibe J, Ogwuegbu M, Egwurugwu J. Heavy metal pollution and human biotoxic effects. Int J Phys Sci. 2007;2(5):112-8.

9. Tchounwou PB, Yedjou CG, Patlolla AK, Sutton DJ. Heavy Metal Toxicity and the Environment. Exp Suppl. 2012;101:133-64.

10. Klimont Z, Streets DG, Gupta S, Cofala J, Lixin F, Ichikawa Y. Anthropogenic emissions of non-methane volatile organic compounds in China. Atmos Environ. 2002;36(8):1309-22.

11. Taylor P, Yunus IS, Kurniawan A, Adityawarman D, Indarto A. Nanotechnologies in water and air pollution treatment. Environ Technol Rev. 2012;(May 2013):37-41.

12. Khin MM, Nair AS, Babu VJ, Murugan R, Ramakrishna S. A review on nanomaterials for environmental remediation. Vol. 5, Energy and Environmental Science. 2012. p. 8075-109.

13. Kampa M, Castanas E. Human health effects of air pollution. Environ Pollut. 2008;151:362-7.

14. Haseena M, Malik MF, Javed A, Arshad S, Asif N. Water pollution and human health . Environ Risk Assess Remediat. 2017;1(3):16-9.

15. Guerra FD, Attia MF, Whitehead DC, Alexis F. Nanotechnology for Environmental Remediation: Materials and Applications. Vol. 23, Molecules (Basel, Switzerland). 2018. p. 1-23.

16. Zhang WX. Nanoscale iron particles for environmental remediation: An overview. Vol. 5, Journal of Nanoparticle Research. 2003. p. 323-32

17. Wang D, Pillai SC, Ho SH, Zeng J, Li Y, Dionysiou DD. Plasmonic-based nanomaterials for environmental remediation. Vol. 237, Applied Catalysis B: Environmental. 2018. p. 721-41.

18. Bates ME, Grieger KD, Trump BD, Keisler JM, Plourde KJ, Linkov I. Emerging Technologies for Environmental Remediation: Integrating Data and Judgment. Environ Sci Technol. 2016;50(1):349-58.

19. Tian Y, Wu M, Liu R, Li Y, Wang D, Tan J, et al. Electrospun membrane of cellulose acetate for heavy metal ion adsorption in water treatment. Carbohydr Polym. 2011:83(2):743-8.

20. Carpenter AW, De Lannoy CF, Wiesner MR. Cellulose nanomaterials in water treatment technologies. Environ Sci Technol. 2015;49(9):5277-87.

21. Ma H, Burger C, Hsiao BS, Chu B. Ultra-fine cellulose nanofibers: New nano-scale materials for water purification. J Mater Chem. 2011;21(21):7507-10.

22. O'Connell DW, Birkinshaw C, O'Dwyer TF. Heavy metal adsorbents prepared from the modification of cellulose: A review. Bioresour Technol. 2008;99(15):6709-24

23. Ahmad S, Pandey A, Pathak VV. Phycoremediation: Algae as Eco-friendly Tools for the Removal of Heavy Metals from Wastewaters. Bioremediation Ind Waste Environ Saf. 2020;53-76

24. Wang S, Sun H, Ang HM, Tadé MO. Adsorptive remediation of environmental pollutants using novel graphene-based nanomaterials. Chem Eng J. 2013;

25. Lee LZ, Abbas M, Zaini A, Tang SH. Porous Nanomaterials for Heavy Metal Removal 20. Handb Ecomater. 2019;469-94.

26. Elham M. Nanotechnology : Future of Environmental Air Pollution Control. Macrothink Inst Online J. 2017:6(2):429-54

27. Mueller NC, Nowack B. Nanoparticles for Remediation: Solving Big Problems with Little Particles. Elements. 2010;6(6):395-400.

28. Klemm D, Heublein B, Fink H, Bohn A. Polymer Science Cellulose: Fascinating Biopolymer and Sustainable Raw Material Angewandte. Chemie Int Ed. 2005;44(22):3358-93.

29. Tursi A, Beneduci A, Chidichimo F, Vietro N De, Chidichimo G. Remediation of hydrocarbons polluted water by hydrophobic functionalized cellulose. Chemosphere. 2018;(201):530-9.

30. Ion VA, Pârvulescu OC, Dobre T. Volatile organic compounds adsorption onto neat and hybrid bacterial cellulose. Appl Surf Sci. 2015;335:137-46.

31. Wang B, Wan Y, Zheng Y, Lee X, Liu T, Yu Z, et al. Technology Alginate-based composites for environmental applications : a critical review. Crit Rev Environ Sci Technol. 2018:0(0):1-39.
32. Hatakeyama H, Hatakeyama T. Lignin Structure, Properties, and Applications. Adv Polym Sci. 2009;1-63.

33. Wang C, Wu S, Jian M, Xie J, Xu L, Yang X, et al. Silk nanofibers as high efficient and lightweight air filter. Nano Res. 2016:1:1-8.

34.Aider M. LWT - Food Science and Technology Chitosan application for active bio-based films production and potential in the food industry : Review. LWT - Food Sci Technol. 2010;43(6):837-42.

35. Abdou ES, Nagy KSA, Elsabee MZ. Extraction and characterization of chitin and chitosan from local sources. Bioresour Technol. 2008;99:1359-67.

36. Khan S, Garg M, Chockalingam S, Gopinath P, Kundu PP. TiO2 doped chitosan/poly (vinyl alcohol) nanocomposite film with enhanced mechanical properties for application in bone tissue regeneration. International Journal of Biological Macromolecules. Elsevier B.V; 2019

37. Toan N Van, Hanh TT. Application of chitosan solutions for rice production in. African J Biotechnol. 2013;12(4):382-4.

38. Al-manhel AJ, Al-hilphy ARS, Niamah AK. Extraction of chitosan , characterisation and its use for water purification. J SAUDI Soc Agric Sci. 2016;

39.Zhao L, Yang S, Yilihamu A, Ma Q, Shi M, Ouyang B, et al. Adsorptive decontamination of $\mathrm{Cu} 2+-$-contaminated water and soil by carboxylated graphene oxide/chitosan/cellulose composite beads. Environ Res. 2019;108779.

40.Carvalho IC, Borsagli FGLM, Alexandra AP, Caldeira CL, Haas DJ, Lage AP, et al. 3D sponges of chemically functionalized chitosan for potential environmental pollution remediation: biosorbents for anionic dye adsorption and 'antibiotic-free ' antibacterial activity. Environ Technol. 2019;0(0):1-21.

41. Yong K, Mooney DJ. Alginate : Properties and biomedical applications. Prog Polym Sci. 2012;37(1):106-26.

42.Boerjan W, Ralph J, Baucher M. Lignin biosynthesis. Annu Rev Plant Biol. 2003;54:519-46.

43. Vanholme R, Morreel K, Ralph J, Boerjan W. Lignin engineering. Curr Opin Plant Biol. 2008;(11):278-85.

44.Parajuli D, Inoue K, Ohto K, Oshima T. Adsorption of heavy metals on crosslinked lignocatechol: a modified lignin gel. React Funct Polym. 2005;62:129-39.

45.Li Z, Ge Y, Wan L. Fabrication of a green porous lignin-based sphere for the removal of lead ions from aqueous media. J Hazard Mater. 2014:

46. Babu KM. Introduction to silk and sericulture. In: Silk. 2019. p. $1-29$.

47. Cao Y, Wang B. Biodegradation of Silk Biomaterials. Int J Mol Sci. 2009;1514-24.

48. Aigner TB, Desimone E, Scheibel T, Engineering B, Aigner TB. Biomedical Applications of Recombinant Silk-Based Materials. Adv Mater. 2018:1-28.

49.Peng B, Yao Z, Wang X, Crombeen M, Gsweene D, Tam KC. Cellulose-based Materials in Wastewater Treatment of Petroleum Industry. Green Energy Environ. 2019;

50.George J. Cellulose nanocrystals: synthesis, functional properties, and applications. Nanotechnology, Sci Appl. 2015;45-54.

51. Kumar M, Turner S. Plant cellulose synthesis: CESA proteins crossing kingdoms. Phytochemistry. 2014;

52. Mcnamara JT, Morgan JLW. A Molecular Description of Cellulose Biosynthesis. Annu Rev Biochem. 2015;84(1):895-921.

53. Maleki SS, Mohammadi K, Ji K. Characterization of Cellulose Synthesis in Plant Cells. Sci World J. 2016;2016.

54.Guerra FD, Campbell ML, Attia MF, Whitehead DC, Alexis F. Capture of Aldehyde VOCs Using a Series of Amine-Functionalized Cellulose Nanocrystals. ChemistrySelect. 2018;3(20):5495-501.

55. Thakur VK, Thakur MK. Processing and characterization of natural cellulose fibers/thermoset polymer composites. Vol. 109, Carbohydrate Polymers. Elsevier Ltd.; 2014. p. 102-17.

56. Nabili A, Fattoum A, Passas R, Elaloui E, Nabili A. EXTRACTION AND CHARACTERIZATION OF CELLULOSE FROM DATE PALM SEEDS ( Phoenix dactylifera $L$.) Laboratory of Pulp. Paper and Graphic Arts Sciences, UMR CNRS 5518 ,. Cellul Chem Technol. 2014:50:9-10. 
57. Mischnick P. Momcilovic D. Chemical Structure Analysis of Starch and Cellulose Derivatives [Internet]. Vol. 64, Advances in Carbohydrate Chemistry and Biochemistry - Volume 64. Elsevier Inc.; 2010. 117-210 p. Available from: http://dx.doi.org/10.1016/ S0065-2318 (10)64004-8

58. Ateia M, Attia MF, Maroli A, Tharayil N, Alexis F, Whitehead DC, et al. Rapid Removal of Poly- and Perfluorinated Alkyl Substances by Poly(ethylenimine)-Functionalized Cellulose Microcrystals at Environmentally Relevant Conditions. Environ Sci Technol Lett. 2018;5(12):764-9

59. Morán Jl, Alvarez VA, Cyras VP, Vázquez A. Extraction of cellulose and preparation of nanocellulose from sisal fibers. Cellulose. 2008;15(1):149-59.

60.Programme UUNE. Biodiversity in Latin America and the Caribbean. 2016. p. 1-5.

61. Almeida MA. Extraction of Bioactive Compounds from Latin American Plants. 2007

62. Luque S, Mart G, Echeverr C, Pacha MJ. Chapter 15 Overview of Biodiversity Loss in South America : A Landscape Perspective for Sustainable Forest Management and Conservation in Temperate Forests. In: Landscape Ecology in Forest Management and Conservation.

63. Valencia R. Composition and structure of an Andean forest fragment in eastern Ecuador. Biodiversity and conservation of Neotropical montane forests. Proc. symposium, New York Botanical Garden, 1993. 1995. p. 239-49.

64. Hokkanen S, Bhatnagar A, Sillanpää M. A review on modification methods to cellulose-based adsorbents to improve adsorption capacity. Water Res. 2016;91:156-73.

65. Bismarck A, Aranbefwi-Askargorta I, Springer J, Lampke T, Wielage B, Stamboulis A, et al. Cellulose Fibers ; Surface Properties and the the Water Uptake Behavior. Polym Compos. 2002;23(5):872-94
66. Manjarrez Nevárez L, Ballinas Casarrubias L, Canto OS, Celzard A, Fierro V, Ibarra Gómez R, et al. Biopolymers-based nanocomposites: Membranes from propionated lignin and cellulose for water purification. Carbohydr Polym. 2011;86(2):732-41.

67. Rinaudo M. Chitin and chitosan : Properties and applications. Prog Polym Sci. 2006;31(7):603-32.

68.68. Moon RJ, Martini A, Nairn J, Simonsen J, Youngblood J. Cellulose nanomaterials review: Structure, properties and nanocomposites. Vol. 40, Chemical Society Reviews. 2011. p. 3941-94.

69. Holant ZR. Biosorption of Heavy Metals. 1995;235-50.

70. Varghese AG, Annie S, Latha PMS. Remediation of heavy metals and dyes from wastewater using cellulose - based adsorbents. Environ Chem Lett. 2018;

71. Guclu G, Gurdag G, Ozgumus S. Competitive Removal of Heavy Metal lons by Cellulose Graft Copolymers. J Appl Polym Sci. 2003;90(8):2034-9.

72. Waly A, Aly AS, Hebeish A. Synthesis and Characterization of Cellulose lon Exchanger . II . Pilot Scale and Utilization in Dye - Heavy Metal Removal. J Appl Polym Sci. 1998;68(13):2151-7.

73. Xiong R, Zhang X, Tian D, Zhou Z, Lu C. Comparing microcrystalline with spherical nanocrystalline cellulose from waste cotton fabrics. Cellulose. 2012;19(4):1189-98.

74. Bravo, I., Figueroa, F., Swasy, M. I., et al. Cellulose particles capture aldehyde VOC pollutants. RSC Adv. 10, 7967-7975 (2020).

Received: 5 February 2020

Accepted: 10 April 2020 